Review

\title{
Acquired Idiopathic Generalized Anhidrosis (AIGA) and Its Complications: Implications for AIGA as an Autoimmune Disease
}

\author{
Reiko Kageyama ${ }^{1, *}$, Tetsuya Honda ${ }^{1}$ and Yoshiki Tokura ${ }^{2}$ (1) \\ 1 Department of Dermatology, Hamamatsu University School of Medicine, Hamamatsu 431-3192, Japan; \\ hontetsu@hama-med.ac.jp \\ 2 Allergic Disease Research Center and Department of Dermatology, Chutoen General Medical Center, \\ Kakegawa 436-8555, Japan; tokura@chutoen-hp.shizuoka.jp \\ * Correspondence: reikok@hama-med.ac.jp
}

Citation: Kageyama, R.; Honda, T.; Tokura, Y. Acquired Idiopathic Generalized Anhidrosis (AIGA) and Its Complications: Implications for AIGA as an Autoimmune Disease. Int J. Mol. Sci. 2021, 22, 8389. https:// doi.org/10.3390/ijms22168389

Academic Editor: Theoharis

C. Theoharides

Received: 29 June 2021

Accepted: 29 July 2021

Published: 4 August 2021

Publisher's Note: MDPI stays neutral with regard to jurisdictional claims in published maps and institutional affiliations.

Copyright: (c) 2021 by the authors. Licensee MDPI, Basel, Switzerland. This article is an open access article distributed under the terms and conditions of the Creative Commons Attribution (CC BY) license (https:// creativecommons.org/licenses/by/ $4.0 /)$.

\begin{abstract}
Acquired idiopathic generalized anhidrosis (AIGA) is a rare disorder in which systemic anhidrosis/hypohidrosis occurs without causative dermatological, metabolic or neurological disorder. Most cases of AIGA have been reported in Asia, especially in Japan, but there have been only a few reports in Europe and the United States. Severe AIGA may result in heatstroke and can reduce quality of life due to restriction of exercise and outdoor works. AIGA is often accompanied by cholinergic urticaria (CholU), and it is thought that AIGA and CholU with anhidrosis/hypohidrosis belong to the same spectrum of the disease. However, the pathophysiology of AIGA has not yet been clarified. Decreased expression of cholinergic receptor M3 on the epithelial cells of eccrine sweat glands is often accompanied by $\mathrm{T}$ cell infiltration around eccrine apparatus, suggesting an immunological mechanism of disordered perspiration. AIGA is occasionally associated with various complications indicative of autoimmune disorders. The association of autoimmune complications further suggests that AIGA is an autoimmune disorder. Studies on complications may lead to a better understanding of the pathophysiology of AIGA.
\end{abstract}

Keywords: acquired idiopathic generalized anhidrosis; cholinergic urticaria; complication; autoimmune disorder

\section{Introduction}

Acquired idiopathic generalized anhidrosis (AIGA) is a rare disorder characterized by the sudden onset of systemic anhidrosis/hypohidrosis without directly causative dermatological, metabolic or neurological disorder [1]. Severe AIGA may result in heatstroke and can reduce quality of life due to restriction of exercise and outdoor works. A high frequency of the association with cholinergic urticaria (CholU) is noted in AIGA [1]. From the dermatological point of view, CholU is the primary nomenclature for this condition [2], and thus, AIGA has been historically reported as "CholU with anhidrosis" or "CholU with hypohidrosis" in the dermatological literature [3]. In the terminology for depressed perspiration, anhidrosis and hypohidrosis represent complete and incomplete lack of sweating, respectively. Currently, it is thought that AIGA and CholU with anhidrosis/hypohidrosis belong to the same spectrum of the disease [2], and not only neurologists but also dermatologists use AIGA in daily practice. Although AIGA is well known to show CholU and associated itch or even pain, the exact frequency of CholU in patients with AIGA has not been investigated. One of the reasons for the lack of research may be that the degree of CholU varies from case to case and endemic investigation on this issue is not easy.

Systemic administration of corticosteroids is recommended for the treatment of AIGA, and there is a report that other immunosuppressive agents such as cyclosporine are also effective $[1,4,5]$. Case reports that have been recently accumulated indicate that patients with AIGA have various complications or comorbidities, including autoimmune disorders. 
These complications may provide some implications to elucidate the pathology of AIGA, possibly because the patients developed AIGA and its complications in parallel via the similar mechanisms. This review article aims to show complications of AIGA in our and reported cases. The present review of literature further clarifies the significance of autoimmune diseases as important complications.

\section{Epidemiology of AIGA and CholU with Anhidrosis/Hypohidrosis}

More than 100 cases of AIGA have been documented worldwide, but no study has been conducted regarding large-scale epidemiology on AIGA, and thus, its exact prevalence is unknown [1,6]. While a vast majority of cases of AIGA have been reported in Asia, especially in Japan, only a few reports have been documented from Europe [6-9] and the United States [10-12]. Accordingly, when we investigated cases of CholU with anhidrosis/hypohidrosis in the literature (until 2010), 26 out of 29 cases were Japanese [3]. Thus, the ethnic differences in the frequency of AIGA definitely exists between Asian and Western populations.

AIGA can occur at any age, but evidence suggests that the prevalent onset age is often in the $20 \mathrm{~s}$ to $40 \mathrm{~s}$. Considering that men of these ages are prone to sweat in their workplaces or upon exercise of daily life, they may easily realize disordered perspiration. There was a report of unusual onset of AIGA in a 2-year-old infant [13]. Provided that such a young patient suffers from AIGA, we should make a careful diagnosis for pediatric cases. In addition, the complaint of low perspiration is not clear in low-aged children under 6 years.

It is considered that AIGA is associated with three pathological conditions: sudomotor neuropathy, idiopathic pure sudomotor failure (IPSF), and sweat gland failure [1]. No attenuation of mental sweating, usually present in the palms/soles and axillae, is noted in IPSF [1]. Since IPSF is considered to account for about $90 \%$ of AIGA, it is regarded as a narrowly defined condition of AIGA. In particular, IPSF is a highly frequent condition in adolescent male patients. This is in accordance with the finding that AIGA is remarkably common in men, accounting for more than $80 \%$ of known cases [1]. AIGA is often accompanied by CholU, and therefore, AIGA and CholU with anhidrosis/hypohidrosis are considered to be within the same disease spectrum [2]. AIGA or IPSF is characterized by pain, which is also a main complication of CholU. On the basis of these epidemiological studies, the diagnostic usage of IPSF is less common than that of AIGA, and AIGA seems to be generally used for the condition.

\section{Two Mechanisms of CholU and Relation to Anhidrosis/Hypohidrosis}

CholU manifests small, itchy and/or painful wheals occurring upon perspiration and mechanically involving acetylcholine (Figure 1). We proposed that CholU can be categorized into two major subtypes: acetylcholine-indirectly induced, sweat allergic type and acetylcholine-directly induced, depressed sweating type [2].

In the former type, acetylcholine (Ach) evokes perspiration, and some sweat antigen(s) leaking from the sweat ducts to the dermis may stimulate mast cells to release histamine. In this type, the ducts might be damaged or obstructed for sweat leakage, and patients frequently exhibit positive autologous sweat skin test, representing "sweat allergy". This hypothesis has been supported by high frequency of positive autologous sweat skin test as well as positive Ach skin test in the patients [14]. In addition to this in vivo test, sweat allergy is also proven in vitro by basophil histamine release test and basophil activation test [14]. Concerning sweat antigens, Malassezia globose-derived substance, MGL_1304, was identified as a major allergen in human sweat for patients with atopic dermatitis and CholU [15]. These patients have high levels of serum IgE to purified MGL_1304 from sweat [15], suggesting that the Malassezia-derived substance plays a causative role for the diseases. 

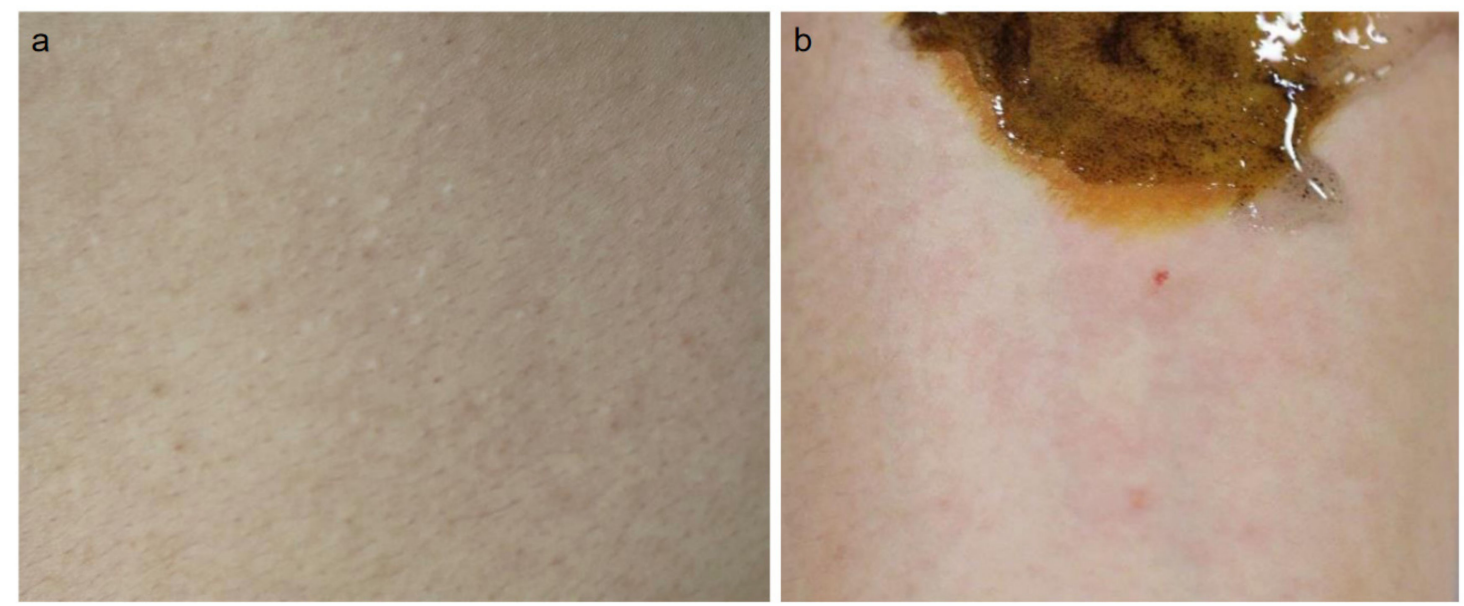

Figure 1. Clinical appearance of cholinergic urticaria (CholU) and acetylcholine (Ach) injection test. Pinpoint wheal of CholU (a). Satellite wheal around intradermal injection of Ach (b).

On the other hand, the latter Ach-mast cell directly interacting type, typically seen as "CholU with anhidrosis and/or hypohidrosis", eccrine sweat gland epithelial cells lack CHRM3 expression. The expression of CHRM3 is completely absent in the anhidrotic areas and only slightly expressed in the hypohidrotic areas. In the hypohidrotic area, where pinpoint wheal occurs, it is hypothesized that released Ach cannot be completely trapped by CHRM3 of eccrine glands and overflows to the adjacent mast cells, leading to wheal formation [3]. Thus, sweat allergy is not a requirement in this depressed sweating type. Although some additional complications, such as angioedema, anaphylaxis, and cold urticaria, have been documented, these two types represent the modes of action of Ach in this enigmatic urticaria.

\section{Immunological Findings in AIGA}

Although there is no sufficiently high level of evidence for its effectiveness, systemic corticosteroid therapy is recommended for the early stages of AIGA or CholU with anhidrosis/hypohidrosis $[1,16]$. This suggests that AIGA and related CholU are mediated via immunological and inflammatory mechanisms. In fact, decreased expression of CHRM3 on the epithelial cells of eccrine sweat glands was found in AIGA or CholU with anhidrosis/hypohidrosis.

It is known that lymphocytes infiltrate around eccrine glands in some patients with CholU. Historically, different lines of studies have suggested that two pathogenic consequences may follow the lymphocytic infiltration. The first consequence is the damage or obstruction of sweat ducts and the resultant dermal leakage of sweat. In the second one, the CHRM3 expression on sweat gland epithelial cells is decreased by the infiltrating lymphocytes. The first and second outcomes are related to the Ach-indirectly induced, sweat allergic type, and the Ach-directly induced, depressed sweating type, respectively. It appears that each of these two consequences occurs almost exclusively. We consider that the second one is more closely associated with lymphocytic infiltration [17]. The infiltrate consists of both $\mathrm{CD} 4^{+}$and $\mathrm{CD} 8^{+} \mathrm{T}$ cells, and as assessed by the expression of CXCR3 and CCR4, both Th1/Tc1 and Th2/Tc2 subpopulations are identifiable [17].

Although the mechanism underlying the decreased expression of CHRM3 by CD4 ${ }^{+}$ and/or $\mathrm{CD}^{+} \mathrm{T}$ cells remains unknown, $\mathrm{T}$ cells chemoattracted by CCL2/MCP-1, CCL5/RANTES, CCL17/TARC are possibly responsible for the reduced CHRM3 expression [17]. In addition to the $\mathrm{T}$ cell-mediated receptor down-modulation theory, some autoantibodies directed against CHRM3 might affect the receptor-mediated signaling (Figure 2). These different lines of evidence prompt us to investigate the autoimmune mechanism underlying AIGA. 
Normal AIGA
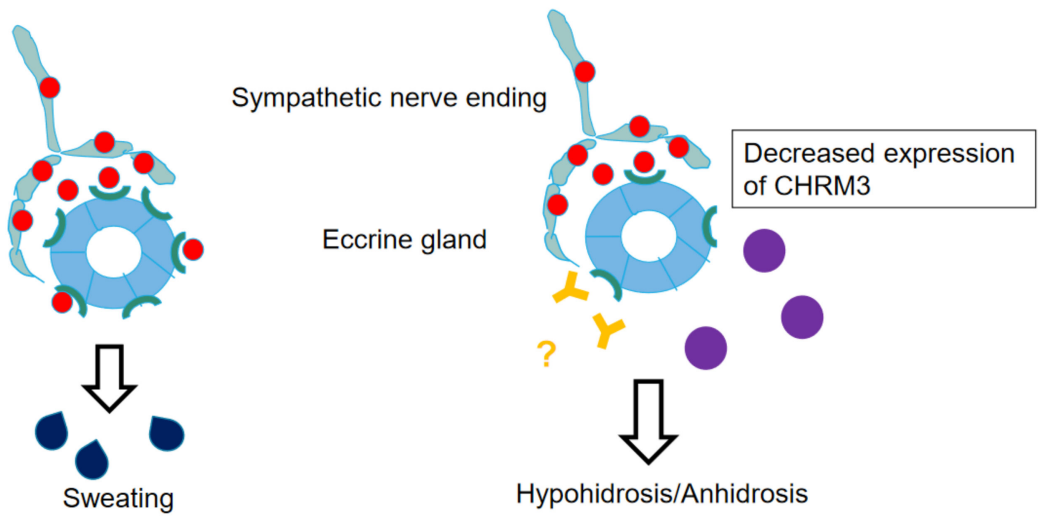

Ach

CHRM3

T cell

Possible unknown autoantibody

Figure 2. Summary of the immune mechanisms underlying AIGA.

\section{Decreased Expression of CHRM3 in AIGA}

The mechanisms underlying AIGA remain to be clarified. In AIGA patients, decreased expression of CHRM3 has often been observed in sweat gland epithelial cells [17]. In addition to the impaired expression of CHRM3, other abnormalities have been proposed in AIGA, such as decreased expression of acetylcholine esterase [17]. There are reports that serum carcinoembryonic antigen (CEA) levels are increased in AIGA patients and CEA may serve as a clinical marker for AIGA activity $[18,19]$. The relationship between aquaporin-5 and AIGA has also been reported and is another issue to be further elucidated [20].

In AIGA, the disordered perspiration is not homogenous over the skin. The skin surface of depressed sweating can be divided into the two areas, anhidrosis and hypohidrosis, as assessed by iodine-starch test [3]. The expression of CHRM3 is completely absent in the anhidrotic areas, while it is incompletely decreased in the hypohidrotic areas. Typically, the predilection sites of anhidrosis include the four extremities (especially the distal parts), while the chest, abdomen and back are hypohidrotic areas. Sweating is usually retained in the palms, soles and axillae. When the patients are successfully treated with corticosteroid pulse therapy, the anhidrotic area is gradually diminished and replaced by the hypohidrotic area, which is then further improved to normal sweating area [16]. The number of lymphocytes infiltrating in eccrine glands inversely correlated with the expression levels of CHRM3 [17,21]. Therefore, it is possible that CHRM3 expression on sweat gland epithelial cells is decreased by the infiltrating lymphocytes.

Ach is historically known to induce degranulation and subsequent histamine release in mast cells [22,23]. Since mast cells infiltrate in the vicinity of sympathetic nerves, these in vitro findings strongly suggest that Ach stimulate mast cells to secrete histamine in certain pathogenic settings. A careful observation reveals that wheals occur on the hypohidrotic areas, but not on the anhidrotic areas. Therefore, CholU tends to take place on the perspiration-recovering area [16]. We are attempting to speculate that, in the hypohidrotic area, Ach released from nerves is not completely trapped by cholinergic receptors of eccrine glands and overflows to the adjacent mast cells, leading to wheal formation. In this scenario, mast cells can produce histamine in response to Ach via CHRM3, whose expression is low but still functional in the hypohidrotic area.

\section{Autoimmune Diseases as Representative Complications or Comorbidities of AIGA}

Various complications or comorbidities have been reported in AIGA. Atopic dermatitis and asthma were well documented, but other diseases presumably caused via autoimmune mechanisms are also associated with AIGA (Table 1). Such diseases are described below with the pathogenic similarities between the complications and AIGA per se. 
Table 1. Summary of our AIGA cases and other reported AIGA cases with complications or comorbidities that are considered to be autoimmune diseases or diseases with presumed autoimmune mechanisms.

\begin{tabular}{|c|c|c|c|c|c|c|c|}
\hline Cases & Age & Sex & $\begin{array}{l}\text { Complication or } \\
\text { Comorbidity }\end{array}$ & $\begin{array}{l}\text { Period from } \\
\text { AIGA Onset } \\
\text { to the First } \\
\text { Visit }\end{array}$ & $\begin{array}{c}\text { Lymphocyte } \\
\text { Infiltration around } \\
\text { the Sweat Glands } \\
\text { in Non-Sweat } \\
\text { Area }\end{array}$ & $\begin{array}{c}\text { CHRM3 } \\
\text { Expression }\end{array}$ & $\begin{array}{c}\text { Clinical } \\
\text { Outcome with } \\
\text { Steroid Pulse } \\
\text { Therapy }\end{array}$ \\
\hline Our case1 & 55 & M & Central diabetes insipidus & 15 years & $\begin{array}{l}\text { Mild } \\
\text { Mild sweat glands } \\
\text { atrophy }\end{array}$ & Decreased & $\begin{array}{l}\text { Improved } \\
\text { sweating }\end{array}$ \\
\hline Our case 2 & 41 & M & Hypogammaglobulinemia & 10 years & $\begin{array}{l}\text { Almost none } \\
\text { Mild sweat glands } \\
\text { atrophy }\end{array}$ & Decreased & $\begin{array}{l}\text { No significant } \\
\text { improvement } \\
\text { in sweating }\end{array}$ \\
\hline Our case 3 & 42 & M & Basedow's disease & 2 years & Mild to moderate & Decreased & $\begin{array}{l}\text { Improved } \\
\text { sweating }\end{array}$ \\
\hline Our case 4 & 32 & M & $\begin{array}{l}\text { Pulmonary sarcoidosis, } \\
\text { Psoriasis vulgaris }\end{array}$ & 3 months & Mild & Decreased & $\begin{array}{l}\text { Improved } \\
\text { sweating }\end{array}$ \\
\hline $\begin{array}{l}\text { Shimoda et al., } \\
2019\end{array}$ & 43 & M & Alopecia areata & 1 year & Mild & $\mathrm{N} / \mathrm{A}$ & $\begin{array}{l}\text { Improved } \\
\text { sweating }\end{array}$ \\
\hline $\begin{array}{l}\text { Kurachi et al., } \\
2018\end{array}$ & 67 & M & Rheumatoid arthritis & 2 months & Almost none & $\mathrm{N} / \mathrm{A}$ & $\begin{array}{l}\text { Improved } \\
\text { sweating }\end{array}$ \\
\hline $\begin{array}{l}\text { Gangadharan } \\
\text { et al., } 2015\end{array}$ & 47 & M & Lichen planus & 3 years & $\begin{array}{c}\text { None } \\
\text { Absence of sweat } \\
\text { glands }\end{array}$ & $\mathrm{N} / \mathrm{A}$ & $\begin{array}{l}\text { Improved } \\
\text { sweating }\end{array}$ \\
\hline $\begin{array}{l}\text { Saito et al., } \\
2015\end{array}$ & 50 & M & Vitiligo vulgaris & 5 months & Moderate & $\mathrm{N} / \mathrm{A}$ & $\begin{array}{l}\text { Improved } \\
\text { sweating }\end{array}$ \\
\hline $\begin{array}{l}\text { Sakaguchi } \\
\text { et al., } 2013\end{array}$ & 45 & M & $\begin{array}{c}\text { Vogt-Koyanagi-Harada } \\
\text { disease }\end{array}$ & 20 years & $\begin{array}{l}\text { Mild } \\
\text { Sweat glands } \\
\text { atrophy }\end{array}$ & $\mathrm{N} / \mathrm{A}$ & $\begin{array}{l}\text { Improved } \\
\text { sweating }\end{array}$ \\
\hline $\begin{array}{l}\text { Ohshima et al., } \\
\qquad 2011\end{array}$ & 41 & M & Crohn's disease & 3 months & None & $\mathrm{N} / \mathrm{A}$ & $\begin{array}{l}\text { Improved } \\
\text { sweating }\end{array}$ \\
\hline $\begin{array}{l}\text { Asahina et al., } \\
2004\end{array}$ & 25 & M & Central diabetes insipidus & 19 months & None & $\mathrm{N} / \mathrm{A}$ & $\begin{array}{l}\text { Improved } \\
\text { sweating }\end{array}$ \\
\hline
\end{tabular}

\subsection{Central Diabetes Insipidus}

Central diabetes insipidus is characterized by hypotonic polyuria due to impairment of vasopressin (AVP) secretion from the posterior pituitary [24]. This disorder may be familial, idiopathic, or secondary [25]. Secondary diabetes insipidus is caused by tumors, infections, trauma, or other processes that damage the hypothalamic-neurohypophysial system. Idiopathic diabetes insipidus is characterized by selective hypofunction of the hypothalamic-neurohypophysial system. Central diabetes insipidus can be accompanied by decreased perspiration. Investigation of the reported cases indicates that there are two types of anhidrosis/hypohidrosis associated with central diabetes insipidus. In one type, decreased perspiration may secondarily occur as a consequence of diabetes insipidus [26], and in the other type, both diabetes insipidus and decreased perspiration may be induced by pathologically similar autoimmune mechanisms [27]. The condition can be caused by lymphocytic infundibuloneurohypophysitis, a disorder estimated as an autoimmune disorder [25], suggesting the latter autoimmune type.

Our patient developed AIGA almost at the same time as the occurrence of central diabetes insipidus [28]. Although his central diabetes insipidus improved with oral administration of desmopressin acetate hydrate, the hypohidrosis had continued, and his histopathological study in the anhidrotic area showed mild lymphocyte infiltration around the sweat glands and mild sweat glands atrophy (Figure 3a). Meanwhile, the patient's hypohidrosis was improved by corticosteroid pulse therapy. This mode of therapeutic action indicates that both diabetes insipidus and the decreased perspiration in our case stem from autoimmunity. 

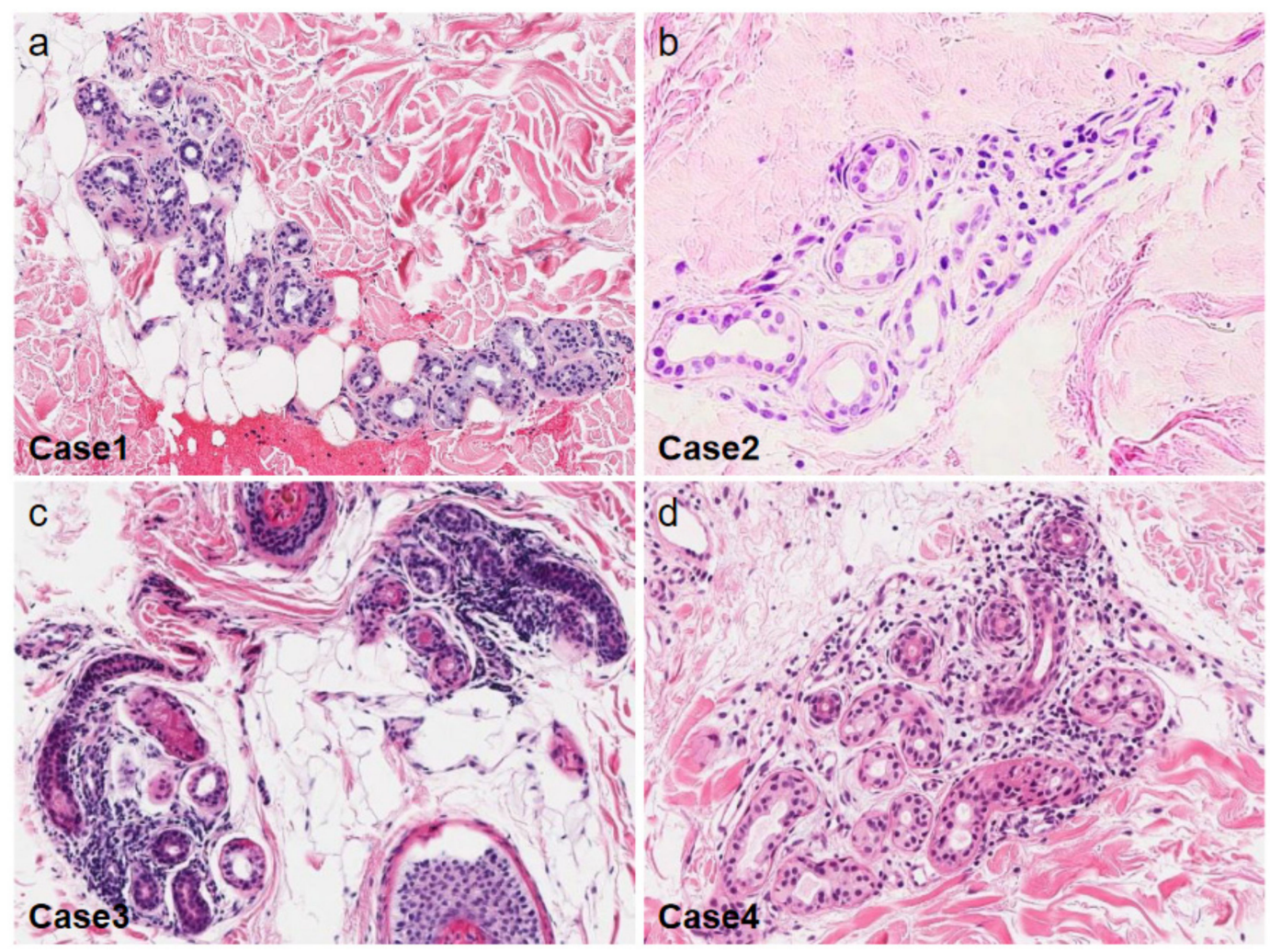

Figure 3. Skin histopathology of the anhidrotic area in our cases. Mild to moderate lymphocyte infiltration around the sweat glands is observed in Cases 1,3 , and 4 (a,c,d, original magnification $\times 40, \times 100$ and $\times 100$ respectively), but scarce in Case 2 (b, original magnification $\times 200$ ) (Hematoxylin-Eosin staining).

There is another case report that central diabetes insipidus was associated with AIGA, and the patient developed central diabetes insipidus 3 years after occurrence of AIGA [27]. In accordance with our case, the patient's hypohidrosis was improved by corticosteroid pulse therapy, while his central diabetes insipidus was alleviated by administration of desmopressin acetate hydrate.

These two cases suggest that AIGA associated with central diabetes insipidus can be improved by only corticosteroid pulse therapy, but not by desmopressin acetate hydrate. In another case, however, administration of desmopressin acetate hydrate improved hypohidrosis as well as diabetes insipidus [26], supporting the notion that anhidrosis/hypohidrosis could occur as a secondary condition of central diabetes insipidus.

The therapeutic effectiveness of desmopressin acetate hydrate on anhidrosis/hypohidrosis is different among these cases. However, at least two cases provide evidence that AIGA is not a secondary condition of diabetes insipidus, but it occurs as an immunological disorder in parallel with central diabetes insipidus. Among various autoimmune diseases, diabetes insipidus has been paid attention as a complication of AIGA. This seems to be derived from the notion that the disordered perspiration is easily estimated as a related condition of diabetes insipidus. Although this mechanism may take place, the immunological mechanisms also contribute to both diseases.

\subsection{Rheumatoid Arthritis}

There is one report of a patient with rheumatoid arthritis who developed AIGA [29]. A 67-year-old man visited a hospital with a 2-month history of hypohidrosis. He had an 8 -year history of rheumatoid arthritis and had been treated with methotrexate, abatacept, and insulin. He had hypohidrosis over his body except for his axillae. Histopathological studies in his anhidrotic area showed a poor lymphocytic infiltrate around the sweat glands 
and a decreased number of sweat glands. He was diagnosed as having AIGA and his hypohidrosis was improved immediately by corticosteroid pulse therapy.

It is interesting to investigate the findings in this case. First, rheumatoid arthritis is a disorder in which both $\mathrm{T}$ cells and antibodies are involved. This raises the possibility that his hypohidrosis could be induced by either of immune reactions or both. Second, he was treated with immunosuppressants, which might result in depressed infiltration of lymphocytes. In any case, the effectiveness of corticosteroid pulse therapy suggests that the patient's hypohidrosis was AIGA. Evaluation of rheumatoid arthritis as a related complication or merely incidental condition is a future issue to be clarified with additional cases.

\subsection{Crohn's Disease}

This inflammatory bowel disease was reported as a comorbidity of AIGA [30]. A 41-year-old man with Crohn's disease developed hypohidrosis 3 months ago. He had hypohidrosis almost all over the skin except for the axillae and right elbow. Histopathological studies of his anhidrotic skin showed no abnormal findings. He was diagnosed as having AIGA. His hypohidrosis was improved by corticosteroid pulse therapy and no relapse was observed.

In Crohn's disease, microbial dysbiosis results in uncontrolled intestinal inflammation, and the intestinal barrier formed by intestinal epithelial cells and the innate immune system are also compromised [31,32]. Acquired and innate $\mathrm{T}$ cell responses to a subset of commensal enteric bacteria operate in Crohn's disease. AIGA might share such T cell responses with Crohn's disease.

\subsection{Alopecia Areata}

AIGA was accompanied by alopecia areata [33]. A 43-year-old man visited a hospital with a one-year-history of hypohidrosis. He had hypohidrosis almost all over his body. Histopathological studies in his anhidrotic area showed mild lymphocyte infiltration around the sweat glands. After diagnosis of AIGA, corticosteroid pulse therapy was initiated. His hypohidrosis was improved by the treatment, but it was relapsed. He developed alopecia areata one year after initiation of the therapy. His hypohidrosis was relapsed in winter season and his alopecia areata also progressed in parallel with exacerbation of hypohidrosis.

Alopecia areata is regarded as a tissue-specific and cell-mediated autoimmune disorder, in which the collapse of hair follicle immune privilege plays a key role $[34,35]$. Antibodies against multiple components of hair follicles almost exclusively attack in the anagen phase, where melanogenesis takes place, suggesting involvement of melanogenesisassociated autoantigens as a target epitope. In the reported cases of AIGA, alopecia areata progressed in parallel with worsened hypohidrosis, suggesting autoimmune mechanisms underlying these two diseases.

\subsection{Vitiligo Vulgaris and Vogt-Koyanagi-Harada Disease}

These diseases have been reported as comorbidities of AIGA [36,37]. Vitiligo vulgaris is an acquired disease in which melanocytes in the skin are decreased or disappear. It is thought to be caused mainly by autoimmune loss of melanocytes from the involved areas [38-40]. Vitiligo vulgaris is frequently associated with autoimmune comorbidities and diseases, such as autoimmune thyroiditis, rheumatoid arthritis, type 1 diabetes, psoriasis, systemic lupus erythematosus, and alopecia areata, suggesting that AIGA shares the autoimmune mechanisms with these representative diseases. It is reported that both antithyroid antibodies and several melanocyte-related autoantibodies are elevated in the sera of patients with vitiligo vulgaris [41,42]. 


\subsection{Lichen Planus}

Lichen planus, which is one of the inflammatory diseases with dyskeratosis of the epidermis, was reported as a complication of AIGA [43]. In most of the affected individuals, the exact cause of lichen planus is unclear, except for medicine as a causative reagent. In lichen planus, some triggers stimulate the immune system to attack epidermal keratinocytes or mucous membranes. In this sense, lichen planus is an autoimmune disorder and associated with various immune-related diseases [44,45].

\section{AIGA-Associated Autoimmune Diseases in Our Cases and Literature}

We experienced four AIGA cases with complications, including central diabetes insipidus [28], hypogammaglobulinemia [46], Basedow's disease, and pulmonary sarcoidosis with psoriasis vulgaris (Table 1). In all of our cases, CHRM3 expression was decreased in the eccrine gland epithelial cells (Figure 4). Histopathological studies in the anhidrotic area showed mild to moderate lymphocyte infiltration around the sweat glands in Cases 1, 3, and 4 (Figure 3). Corticosteroid pulse therapy was effective for the reduced perspiration in three out of four cases (Figure 5).
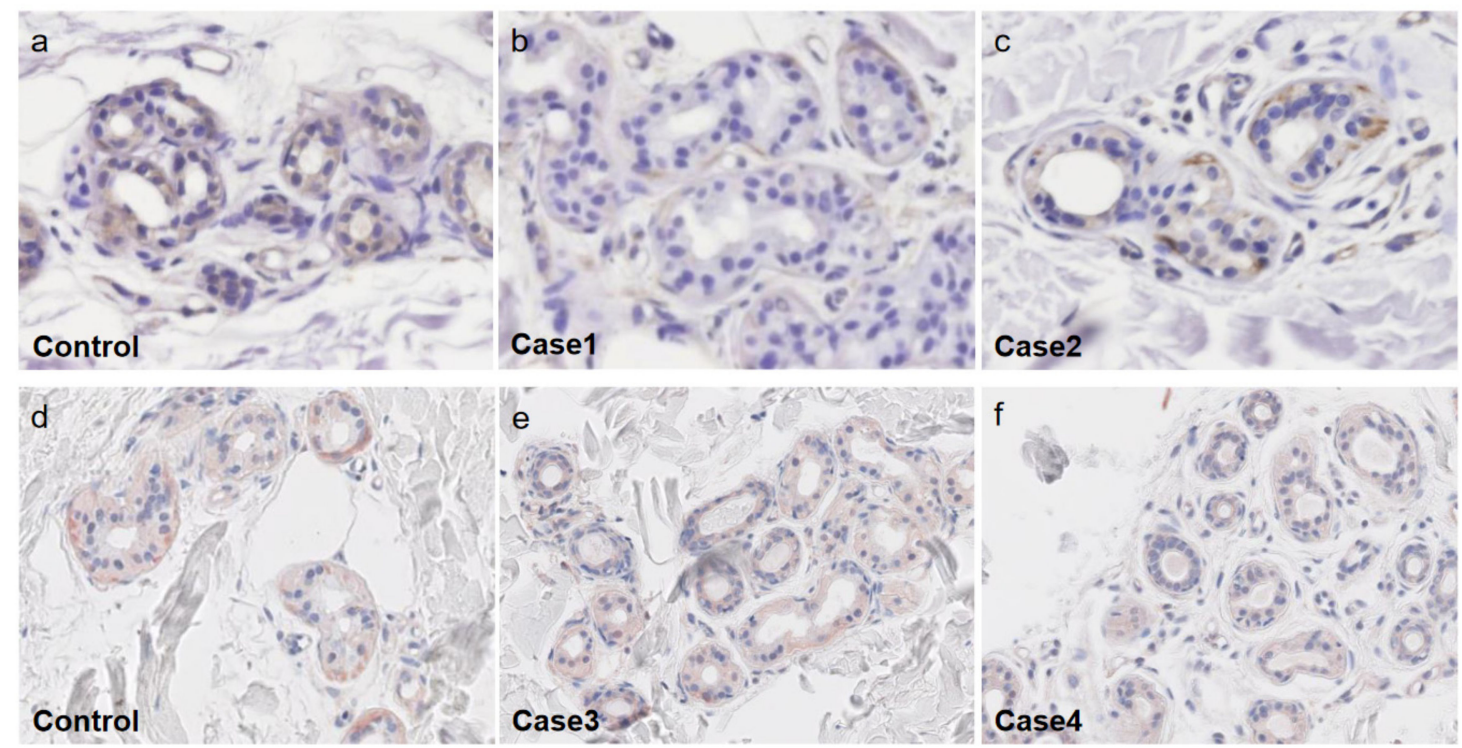

Figure 4. Immunohistochemical staining of cholinergic receptor M3 (CHRM3) at the anhidrotic area in our cases. The upper and lower columns were stained independently. Decreased expression of the CHRM3 (brown signals) is observed in sweat gland epithelial cells $(\mathbf{b}, \mathbf{c}, \mathbf{e}, \mathbf{f}$, original magnification $\times 200, \times 200, \times 100$ and $\times 100$ respectively) compared with control (a,d, original magnification $\times 200$ and $\times 100$ respectively).

The complications in our cases were characterized by presumed autoimmune mechanisms, supporting the notion that patients with AIGA have a high frequency of autoimmune disorders. Accordingly, histopathological examination of the anhidrotic/hypohidrotic skin in AIGA showed infiltration of $\mathrm{CD}^{+} \mathrm{T}$ cells around the eccrine sweat glands, suggesting that AIGA is induced by autoimmune T cell reactions. In this context, there was reported an interesting case of metastatic melanoma in which the patient developed AIGA after treatment with an immune checkpoint inhibitor [47]. As complications, the patient had vitiligo, gastritis, and hepatitis as adverse immune events and subsequently developed AIGA. The skin biopsy specimen taken from the anhidrotic area demonstrated a marked peri-eccrine lymphocyte infiltration. This patient's sweating disorder was improved by systemic corticosteroid administration. This observation supports the concept that the patient's anhidrosis/hypohidrosis is a lymphocyte-mediated adverse immune event of the immunotherapy. It is also suggested that AIGA may be induced by autoimmune $\mathrm{T}$ cell reactions. 

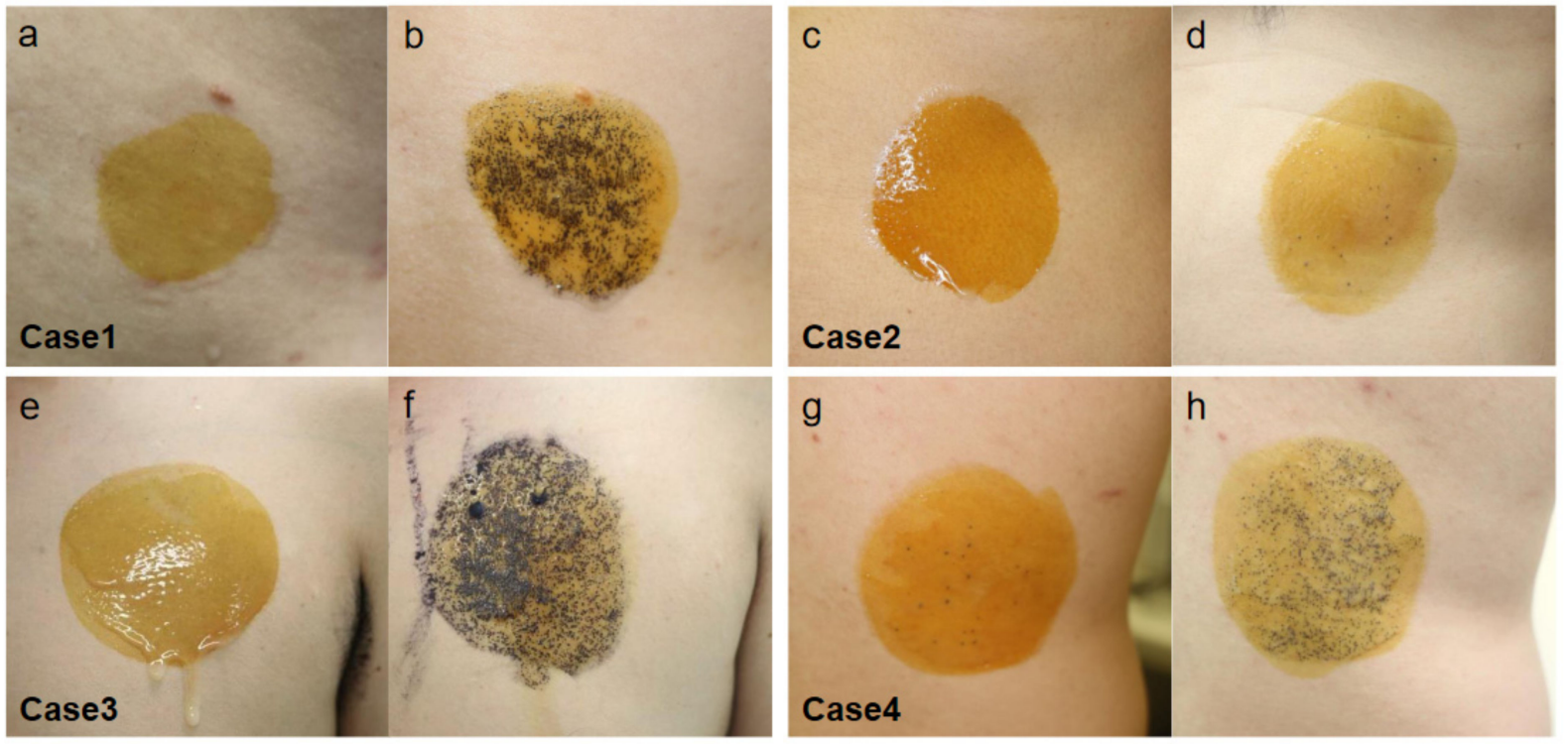

Figure 5. Thermoregulatory sweat test by Minor method using the iodine-starch reaction in our cases. No sweat is observed before treatment in all cases $(\mathbf{a}, \mathbf{c}, \mathbf{e}, \mathbf{g})$. Sweating is observed after corticosteroid pulse therapy in Cases 1,3 , and 4 (b,f, h), but not in Case 2 (d).

It has been reported that anti-CHRM3 autoantibodies in the sera were detected in one of 12 AIGA patients [48]. In addition to autoreactive T cells, therefore, autoantibodies to the acetylcholine receptor might be responsible for the depressed perspiration in these autoimmune diseases. Peri-glandular Lymphocytic infiltrates can be found in AIGA, but not in all cases, raising a possibility that antibodies play a role in lymphocyte-paucity cases. There is an idea that lymphocytic infiltrates are likely to be found in the early onset of AIGA [49], suggesting an alternative possibility that lymphocytes disappear in the course.

\section{Conclusions}

The association of autoimmune complications implies that AIGA is an autoimmune disorder. It has been reported that both $\mathrm{CD} 4^{+}$and $\mathrm{CD} 8^{+} \mathrm{T}$ cells infiltrate around eccrine gland epithelial cells in AIGA and CholU with anhidrosis/hypohidrosis [17]. Further T cell subsets have not been investigated in AIGA. The complications provide insights for the subpopulations of T cells. Th17 cells are involved in the pathology of Crohn's disease and rheumatoid arthritis [32,50]. In addition, skin resident memory T cells induce psoriasis and vitiligo [51]. In addition to Th and Tc cells, these $\mathrm{T}$ cell populations are possible candidates for the pathology.

Based on the autoimmune mechanism, corticosteroid therapy, and in particular corticosteroid pulse therapy, is recommended as the primary treatment for AIGA [1], although it does not improve all cases. It has been reported that younger age and delay from the onset to the treatment are negative factors for the effectiveness of AIGA treatment [4]. Seasonal factors have a significant effect on both treatment and recurrence for AIGA in Japan [4]. The effectiveness of oral administration of cyclosporine and Chinese herbal medicine has been reported in a limited number of the patients [5]. Studies on complications may lead to a better understanding of the pathophysiology of AIGA. Future studies are required to elucidate the pathophysiology of AIGA.

Author Contributions: Conceptualization, R.K. and Y.T.; methodology, R.K. and Y.T.; validation, R.K., T.H. and Y.T.; writing-original draft preparation, R.K.; writing-review and editing, R.K., T.H. and Y.T.; visualization, R.K.; supervision, Y.T.; project administration, R.K. All authors have read and agreed to the published version of the manuscript.

Funding: This research received no external funding. 
Institutional Review Board Statement: The study was conducted according to the guidelines of the Declaration of Helsinki, and approved by the Institutional Review Board of Hamamatsu University School of Medicine.

Informed Consent Statement: Informed consent was obtained from all subjects involved in the study.

Conflicts of Interest: The authors declare no conflict of interest.

\section{References}

1. Munetsugu, T.; Fujimoto, T.; Oshima, Y.; Sano, K.; Murota, H.; Satoh, T.; Iwase, S.; Asahina, M.; Nakazato, Y.; Yokozeki, H. Revised guideline for the diagnosis and treatment of acquired idiopathic generalized anhidrosis in Japan. J. Dermatol. 2017, 44, 394-400. [CrossRef] [PubMed]

2. Tokura, Y. Direct and indirect action modes of acetylcholine in cholinergic urticaria. Allergol. Int. 2021, 70, 39-44. [CrossRef]

3. Sawada, Y.; Nakamura, M.; Bito, T.; Fukamachi, S.; Kabashima, R.; Sugita, K.; Hino, R.; Tokura, Y. Cholinergic urticaria: Studies on the muscarinic cholinergic receptor M3 in anhidrotic and hypohidrotic skin. J. Investig. Dermatol. 2010, 130, 2683-2686. [CrossRef]

4. Iida, T.; Nakamura, M.; Inazawa, M.; Munetsugu, T.; Nishida, M.; Fujimoto, T.; Sasaki, Y.; Ohshima, Y.; Nakazato, Y.; Namiki, T.; et al. Prognosis after steroid pulse therapy and seasonal effect in acquired idiopathic generalized anhidrosis. J. Dermatol. 2021, 48, 271-278.

5. Mok, Z.R.; Tey, H.L. Acquired idiopathic generalized anhidrosis: Successful treatment with cyclosporine in two cases. Dermatol. Ther. 2018, 31, e12579.

6. Pargfrieder, C.; Struhal, W.; Sega, W.; Klein, G.; Sepp, N.; Exler, G. Acquired idiopathic generalized anhidrosis in a young Austrian patient. JAAD Case Rep. 2018, 4, 222-225. [CrossRef]

7. Palm, F.; Loser, C.; Gronau, W.; Voigtlander, V.; Grau, A.J. Successful treatment of acquired idiopathic generalized anhidrosis. Neurology 2007, 68, 532-533. [CrossRef]

8. Wolinia, U. Acquired idiopathic generalized anhidrosis. J. Dermatol. Case Rep. 2014, 8, 120-121. [CrossRef]

9. Ruiz-Villaverde, R.; Sanchez Cano, D. Acquired idiopathic generalized anhidrosis. Actas Dermosifiliogr. 2006, 97, 551-552. [CrossRef]

10. Brantely, E.; Mutasim, D.F.; Heaton, C. Acquired idiopathic generalized anhidrosis: Case report. Cutis 2011, 87, $21-23$.

11. Kay, D.; Maibach, H. Pruritus and acquired anhidrosis-two unusual cases. Arch. Dermatol. 1969, 100, 291-293. [CrossRef]

12. Weigand, D.; Everett, M. Acquired generalized anhidrosis. Arch. Dermatol. 1966, 93, 443-445. [CrossRef]

13. Ohshima, Y.; Yanagishita, T.; Ito, K.; Tamada, Y.; Nishimura, N.; Inukai, Y.; Iwase, S.; Watanabe, D. A case of acquired idiopathic generalized anhidrosis in a 2-year-old infant. J. Eur. Acad. Dermatol. Venereol. 2015, 29, 1446-1448. [CrossRef] [PubMed]

14. Hiragun, T.; Hiragun, M.; Ishii, K.; Kan, T.; Hide, M. Sweat allergy: Extrinsic or intrinsic? J. Dermatol. Sci. 2017, 87, 3-9. [CrossRef] [PubMed]

15. Hiragun, T.; Ishii, K.; Hiragun, M.; Suzuki, H.; Kan, T.; Mihara, S.; Yanase, Y.; Bartels, J.; Schroder, J.M.; Hide, M. Fungal protein MGL_1304 in sweat is an allergen for atopic dermatitis patients. J. Allergy Clin. Immunol. 2013, 132, 608-615. [CrossRef] [PubMed]

16. Kuriyama, S.; Aoshima, M.; Tokura, Y. Studies on hidrotic condition and sweating recovery after corticosteroid-pulse therapy in seven patients with acquired idiopathic generalized anhidrosis/anhidrotic or hypohidrotic cholinergic urticarial. Jpn. J. Dermatol. 2016, 126, 1263-1271. (In Japanese)

17. Sawada, Y.; Nakamura, M.; Bito, T.; Sakabe, J.; Kabashima-Kubo, R.; Hino, R.; Kobayashi, M.; Tokura, Y. Decreased expression of acetylcholine esterase in cholinergic urticarial with hypohidrosis or anhidrosis. J. Investig. Dermatol. 2014, 134, 276-279. [CrossRef] [PubMed]

18. Honma, M.; Iinuma, S.; Kanno, K.; Komatsu, S.; Minami-Hori, M.; Ishida-Yamamoto, A. Correlation of disease activity and serum level of carcinoembryonic antigen in acquired idiopathic generalized anhidrosis: A case report. J. Dermatol. 2015, 42, 900-902. [CrossRef]

19. Honma, M.; Iinuma, S.A.; Kanno, K.; Komatsu, S.; Minami-Hori, M.; Iizuka, H.; Ishida-Yamamoto, A. Serum carcinoembryonic antigen (CEA) as a clinical marker in acquired idiopathic generalized anhidrosis: A close correlation between serum CEA level and disease activity. J. Eur. Acad. Dermatol. Venereol. 2016, 30, 1379-1383. [CrossRef]

20. Iizuka, T.; Suzuki, T.; Nakano, K.; Sueki, H. Immunolocalization of aquaporin-5 in normal human skin and hypohidrotic skin diseases. J. Dermatol. 2012, 39, 344-349. [CrossRef]

21. Haustein, U.F.; Schliebs, R.; Schaller, J. Changes in muscarinic acetylcholine receptor binding in skin slices of cholinergic urticaria. Acta Derm-Venereol. 1990, 70, 208-211. [PubMed]

22. Fantozzi, R.; Masini, E.; Blandina, P.; Mannaioni, P.F.; Bani-Sacchi, T. Release of histamine from rat mast cells by acetylcholine. Nature 1978, 273, 473-474. [CrossRef] [PubMed]

23. Blandina, P.; Fantozzi, R.; Mannaioni, P.F.; Masini, E. Characteristics of histamine release evoked by acetylcholine in isolated rat mast cells. J. Physiol. 1980, 301, 281-293. [CrossRef] [PubMed]

24. Garrahy, A.; Moran, C.; Thompson, C.J. Diagnosis and management of central diabetes insipidus in adults. Clin. Endocrinol. 2019, 90, 23-30. [CrossRef]

25. Imura, H.; Nakao, K.; Shimatsu, A.; Ogawa, Y.; Sando, T.; Fujisawa, I.; Yamabe, H. Lymphocytic infundibuloneurohypophysitis as a cause of central diabetes insipidus. N. Engl. J. Med. 1993, 329, 683-689. [CrossRef] [PubMed] 
26. Uchiyama, A.; Tago, O.; Motegi, S.; Hattori, T.; Nagai, Y.; Takahashi, M.; Arakawa, K.; Ishikawa, O. A case of diabetes insipidus diagnosed from the development of acquired systemic anhidrosis. Jpn. J. Clin. Dermatol. 2013, 67, 681-684. (In Japanese)

27. Asahina, M.; Suzuki, A.; Tamura, N.; Yoshida, T.; Hattori, T. A case of acquired idiopathic generalized anhidrosis that developed central diabetes insipidus during the course. Jpn. J. Perspirat. Res. 2004, 11, 12-14. (In Japanese)

28. Imura, K.; Kasuya, A.; Tokura, Y. Acquired idiopathic generalized anhidrosis: A case accompanied by central diabetes insipidus J. Vis. Dermatol. 2020, 19, 237-239. (In Japanese)

29. Kurachi, H.; Kurihara, Y.; Kobayashi, K.; Ouchi, T.; Funakoshi, T.; Amagai, M.; Yamagami, J. A case of acquired idiopathic generalized anhidrosis that developed in patients with rheumatoid arthritis and diabetes. Jpn. J. Dermatol. 2018, 128, 72. (In Japanese)

30. Ohshima, Y.; Itoh, K.; Tamada, Y.; Watanabe, D.; Nishimura, N.; Iwase, S.; Sugenoya, J. Treatment of patients with acquired idiopathic generalized anhidrosis. Jpn. J. Perspirat. Res. 2011, 18, 3-6. (In Japanese)

31. Ramos, G.P.; Papadakis, K.A. Mechanisms of disease: Inflammatory bowel diseases. Mayo. Clin. Proc. 2019, 94, 155-165. [CrossRef]

32. Geremia, A.; Biancheri, P.; Allan, P.; Corazza, G.R.; Sabatino, A.D. Innate and adaptive immunity in inflammatory bowel disease. Autoimmun. Rev. 2014, 13, 3-10. [CrossRef] [PubMed]

33. Shimoda, Y.; Mizukawa, Y.; Yamazaki, Y.; Ohyama, M. A case of acquired idiopathic generalized anhidrosis with alopecia areata. Nishinihon J. Dermatol. 2019, 81, 240. (In Japanese)

34. Ito, T.; Tokura, Y. The role of cytokines and chemokines in the T-cell-mediated autoimmune process in alopecia areata. Exp. Dermatol. 2014, 23, 787-791.

35. Zeberkiewicz, M.; Rudnicka, L.; Malejczyk, J. Immunology of alopecia areata. Cent Eur. J. Immunol. 2020, 45, 325-333.

36. Saito, H.; Yamada, T. A case of acquired idiopathic generalized anhidrosis with vitiligo vulgaris that developed after influenza infection. Jpn. J. Perspirat. Res. 2015, 22, 7-9. (In Japanese)

37. Sakaguchi, M.; Tsuruta, D.; Ishii, N.; Hamada, T.; Ohata, C.; Furumura, M.; Hashimoto, T. Development of acquired idiopathic generalized anhidrosis in a case of Vogt-Koyanagi-Harada disease. Eur. J. Dermatol. 2013, 23, 724-725. [CrossRef] [PubMed]

38. Le Poole, I.C.; Wankowicz-Kalinska, A.; Van den Wijngaard, R.M.; Nickoloff, B.J.; Das, P.K. Autoimmune aspects of depigmentation in vitiligo. J. Investig. Dermatol. Symp. Proc. 2004, 9, 68-72.

39. Narita, T.; Oiso, N.; Fukai, K.; Kabashima, K.; Kawada, A.; Suzuki, T. Generalized vitiligo and associated autoimmune diseases in Japanese patients and their families. Allergol. Int. 2011, 60, 505-508. [CrossRef]

40. Oiso, N.; Suzuki, T.; Fukai, K.; Katayama, I.; Kawada, A. Nonsegmental vitiligo and autoimmune mechanism. Dermatol. Res. Pract. 2011, 2011, 1. [CrossRef]

41. Kemp, E.H.; Gawkrodger, D.J.; Watson, P.F.; Weetman, A.P. Immunoprecipitation of melanogenic enzyme autoantigens with vitiligo sera: Evidence for cross-reactive autoantibodies to tyrosinase and tyrosinase-related protein-2 (TRP-2). Clin. Exp. Immunol. 1997, 109, 495-500.

42. Vrijman, C.; Kroon, M.W.; Limpens, J.; Leeflang, M.M.G.; Luiten, R.M.; Van der Veen, J.P.W.; Wolkerstorfer, A.; Spuls, P.I. The prevalence of thyroid disease in ptients with vitiligo: A systemic review. Br. J. Dermatol. 2012, 167, 1224-1235.

43. Gangadharan, G.; Citron, S.; Surendran, D. Acquired idiopathic generalized anhidrosis. Indian J. Dermatol. $2015,60,422$. [CrossRef]

44. Mushtaq, S. Lichen planus and alopecia areata co-localization. Indian J. Dermatol. 2021, 66, 101-103. [CrossRef] [PubMed]

45. Cojocaru, M.; Cojocaru, I.M.; Silosi, I. Multiple autoimmune syndrome. Maedica 2010, 5, 132-134.

46. Ogura, Y.; Hanai, S.; Kageyama, R.; Aoshima, M.; Ohtsuka, K.; Yagi, H.; Tokura, Y. A case of acquired idiopathic generalized anhidrosis accompanied by hypogammaglobulinemia. Jpn. J. Clin. Dermatol. 2020, 74, 1015-1020. (In Japanese)

47. Kersh, A.E.; Schuchter, L.M.; Elenitsas, R.; Chu, E.Y. Hypohidrosis as an immune-related adverse event of checkpoint inhibitor therapy. Immunotherapy 2020, 12, 951-956. [CrossRef]

48. Asahina, M.; Sano, K.; Fujinuma, Y.; Kuwabara, S. Investigation of antimuscarinic receptor autoantibodies in patients with acquired idiopathic generalized anhidrosis. Intern. Med. 2013, 52, 2733-2737. [CrossRef]

49. Yanagishita, T. Acquired idiopathic generalized anhidrosis. Jpn. J. Dermatol. 2021, 131, 35-41. (In Japanese)

50. Yang, P.; Qian, F.Y.; Zhang, M.F.; Xu, A.L.; Wang, X.; Jiang, B.P.; Zhou, L.L. Th17 cell pathogenicity and plasticity in rheumatoid arthritis. J. Leukoc. Biol. 2019, 106, 1233-1240.

51. Tokura, Y.; Phadungsaksawasdi, P.; Kurihara, K.; Fujiyama, T.; Honda, T. Pathophysiology of skin resident memory T cells. Front. Immunol. 2021, 11, 618897. [CrossRef] [PubMed] 